\title{
Pós-modernidade ou o quê? Reflexões acerca do aqui-agora ${ }^{1}$
}

\author{
¿Posmodernidad o qué? Reflexiones sobre el aquí-ahora \\ Postmodernity or what? Reflections on the here-now
}

\author{
Me. Fabio Jarbeson da Silva Trajano
}

\begin{abstract}
Resumo
Desde sua fase incipiente até o presente momento a pós-modernidade já passou por consideráveis transformações, que, inevitavelmente, também afetaram a natureza do diálogo travado por ela tanto com o passado como com o futuro. Nenhuma surpresa, portanto, que para alguns já se deva falar de uma era da hipermodernidade. $\mathrm{O}$ objetivo deste ensaio é precisamente analisar algumas dessas principais mudanças em diversos aspectos sociais, bem como de que forma e até que ponto elas afetam e podem ser observadas no aquiagora. Para tal fim, se levará em conta alguns posicionamentos teóricos sobre o tema, como os de Gilles Lipovetsky e Zygmunt Bauman. Do mesmo modo, verificar-se-á alguns exemplos de como essa realidade, por vezes material, por vezes virtual, tem marcado presença na literatura. Após refletir sobre as questões propostas neste artigo, o leitor não apenas será capaz de apreender alguns dos mecanismos negativos desta nova fase da época pós-moderna, mas também, espera-se, de contribuir individual e coletivamente para superá-los.
\end{abstract}

Palavras-Chave: Pós-modernidade; Hipermodernidade; Literatura; Felicidade; Consumismo.

\section{Resumen}

Desde su fase incipiente hasta el momento presente, la posmodernidad ya ha sufrido considerables transformaciones que, inevitablemente, también afectaron la naturaleza del diálogo que entabla tanto con el pasado como con el futuro. No es de extrañar, por lo tanto, que para algunos ya sea necesario hablar de una era de la hipermodernidad. El propósito de este ensayo es precisamente analizar algunos de estos principales cambios en diversos aspectos sociales, así como de qué manera y en qué medida afectan y pueden observarse en el aquí-ahora. Para ello, se tendrán en cuenta algunas posiciones teóricas sobre el tema, como las de Gilles Lipovetsky y Zygmunt Bauman. Del mismo modo, serán verificados algunos ejemplos de cómo esta realidad, a veces material, a veces virtual, ha estado presente en la literatura. Tras reflexionar sobre las cuestiones propuestas en este artículo, el lector no solo podrá captar algunos de los mecanismos negativos de esta nueva etapa de la era posmoderna, sino que también, se espera, contribuya individual y colectivamente a superarlos.

Palabras claves: Posmodernidad; Hipermodernidad; Literatura; Felicidad; Consumismo.

\begin{abstract}
Since its incipient stage up to the present moment, postmodernity has undergone considerable transformations which have also inevitably affected the nature of the dialogue it has had with both the past and the future. No surprise, then, that some believe these days should be referred to as the age of hypermodernity. The purpose of this essay is precisely to analyze some of these major changes in various social aspects, as well as how and to what extent they affect and can be observed in the here-now. To this end, some theoretical positions on the subject, such as those of Gilles Lipovetsky and Zygmunt Bauman, will be taken into account. Likewise, some examples of how this reality, at times material, at other times virtual, has been present in literature will be considered. After brooding over the points proposed in this article, the reader will not only be able to apprehend
\end{abstract}

\footnotetext{
${ }^{1}$ Todas as citações provenientes do inglês são versões minhas. Todas las citas del inglés son traducciones mías al portugués. All quotes from English are my translation into Portuguese.

${ }^{2}$ Mestre em Literaturas de Língua Inglesa; Centro de Pesquisa e Formação Continuada Paulo Freire (CPFPF) / Secretaria Municipal de Educação de Duque de Caxias (SME); Duque de Caxias, Rio de Janeiro, Brasil; lightuniverse@hotmail.com
} 
some of the negative mechanisms of this new phase of the postmodern era, but also, hopefully, contribute individually and collectively to overcome them.

Keywords: Postmodernity; Hypermodernity; Literature; Happiness; Consumerism.

Não é incomum observar-se tentativas de prover um entendimento conciso do conceito denominado pós-modernidade por meramente se traçar paralelos com o pós-modernismo. De modo geral, a diferença básica entre os dois termos é que o pós-modernismo está principalmente relacionado ao mundo das artes, bem como a acontecimentos culturais e intelectuais, e a pós-modernidade a configurações de caráter histórico e sociológico, notoriamente marcadas pelo surgimento de um novo modelo de sociedade. Segundo Philip Smith e Alexander Riley:

[o] pós-modernismo tem várias dimensões. Refere-se, primeiramente, a um estilo estético e artístico que rejeita os códigos estéticos e artísticos do modernismo. Ele também abarca uma posição filosófica e teórica que provém do pós-estruturalismo e rejeita os dogmas do pensamento modernista.

A pós-modernidade se refere a um estágio de desenvolvimento social que acreditase estar além daquele da modernidade. Um sinônimo aqui é era pós-moderna. A ideia chave é que houve uma mudança decisiva e radical em uma economia pósindustrial organizada ao redor da cultura e do consumo cultural, dos meios de comunicação e da tecnologia da informação (SMITH; RILEY, 2009, p. 207).

No entanto, tais definições não bastam para abranger a amplitude do que vem a ser a pós-modernidade, muito menos para elucidá-la nos devidos grau e profundidade. Desnecessário dizer, então, que com justiça prosseguem as indagações: o que é a pósmodernidade? E como ela se manifesta precisamente nos dias de hoje?

Consoante Saul Fucks, o período pós-moderno, o qual ele nomeia "sociedade do conhecimento", teve início em meados do século XX e foi antecedido por uma sociedade moderna cujos primórdios datam de meados do século XVII (FUCKS, 2003, p. 100). É digno de nota, contudo, que, apesar da inquestionável ruptura paradigmática, essa transição foi caracterizada por uma concomitante (des)continuidade, um processo do gênero tanto/quanto e não ou/ou. Dentre os aspectos que assumiram outra posição, adquiriram outro significado e, por isso mesmo, indicam que a interrupção paradigmática não foi absoluta, visto que eles acompanharam as transformações do capitalismo, Fucks destaca "a competitividade, a eficiência, a luta de classes, a propriedade privada dos meios de produção, o objetivo do lucro máximo, do consumismo, do individualismo, do uso da racionalidade instrumental, etc" (FUCKS, 2003, p. 76). 
Em contrapartida, a associação de determinados fatores históricos favoreceu o alvorecer da sociedade pós-moderna e de seu ritmo frenético. Como sendo os principais fatores históricos, Fucks ressalta as inovações tecnológicas da informática; as crises do capitalismo e a liquidificação das fronteiras nacionais; a ebulição de movimentos socioculturais, tais quais o feminismo, a mobilização negra por direitos civis e a resistência gay que marcaram a década de 60 e cujos resultados são notórios atualmente; a ruína do mundo comunista; e o rápido progresso nos campos da biologia, genética e bioengenharia (FUCKS, 2003, p. 76-77).

Deveras, todos esses fatores supracitados estão (in)diretamente, com maior ou menor ênfase, relacionados ao que pode ser considerado o marco mor da época pós-moderna: a busca desesperada por felicidade mediante diversas práticas de consumo exacerbado. A título de exemplo, em oposição ao modo como o fenômeno da obsolescência ocorria na modernidade, quando os produtos eram projetados com uma vida útil previamente antecipada como maneira de manter a produção, atualmente é a própria inovação tecnológica que desempenha o papel de fomentadora da produção por tornar as mercadorias rapidamente ultrapassadas e indesejáveis (BAUMAN, 2001, p. 100). Do mesmo modo, ao contrário da era moderna, quando o motivador de produção e consumo era a necessidade, no universo pós-moderno quem determina a premência é a combinação da velocidade com que são inseridos no mercado produtos mais rápidos-novos-eficientes, e da atuação de poderosas técnicas de propaganda que padronizam o pensamento e despertam o desejo desenfreado de compra (FUCKS, 2003, p. 77-78). Seja como for, conforme se pode antecipar fazendo uso das palavras do filósofo francês Gilles Lipovetsky com relação a essa lógica do sempre mais e sua pulsão neofílica, "[p]roduzimos e consumimos cada vez mais, mas isso não nos torna mais felizes" (LIPOVETSKY, 2006, p. 286-287).

No que concerne a essa etapa sócio-histórica, Lipovetsky defende que a noção de pósmodernidade só passa a ser patente a partir do final da década de 70, ocasião em que já se percebia ares de uma sociedade mais diversa, com muito mais escolhas e desobrigada do peso imposto pelas expectativas futuras da modernidade (LIPOVETSKY, 2004, p. 51). De fato, depois de "duas guerras mundiais, dos extermínios em massa, do totalitarismo, do perigo atômico e, mais recentemente, da degradação dos ecossistemas e das ameaças biotecnológicas" (LIPOVETSKY, 2006, p. 287), não surpreende que se tenha tornado mais forte o rechaço aos ideais de progresso dos tempos modernos em favor do imediatismo do aqui-agora e sua inerente brevidade, assim como das normas consumistas focadas no presente. 
Curiosamente, porém, embora reconheça a importância da pós-modernidade como período questionador da aparente solidez da racionalidade moderna e das grandes ideologias, Lipovetsky a vê como nada mais que uma fase incubadora da necessária transição da modernidade para aquilo que ele chama de hipermodernidade (LIPOVETSKY, 2004, p. 58): “[e]ssa época [pós-moderna] terminou. Hipercapitalismo, hiperclasse, hiperpotência, hiperterrorismo, hiperindividualismo, hipermercado, hipertexto - o que mais não é hiper? $\mathrm{O}$ que mais não expõe uma modernidade elevada à potência superlativa?” (LIPOVETSKY, 2004, p. 53, grifo do autor). Segundo o filósofo, o estágio intermediário pós-moderno possibilitou um relaxamento social em decorrência da diminuição das pressões e restrições que tipificaram a modernidade. Contudo, quiçá em consequência, entre outras coisas, de carecer de uma postura e definição mais precisas, além de ser demasiado ambíguo e abundante em indeterminações, Lipovetsky acredita que esse suposto alívio inicial fornecido pela pós-modernidade já perdeu espaço para a sensação de insegurança e os temores que marcam o momento presente. Com efeito, esses são aspectos-chave que abrem caminho para a sua hipermodernidade e justificam sua afirmação de que "o rótulo pós-moderno, que antes anunciava um nascimento, tornou-se um vestígio do passado, um 'lugar da memória"” (LIPOVETSKY, 2004, p. 64-65, grifo do autor).

Não obstante, controvérsias à parte, mantém-se aqui o posicionamento de Fucks com respeito ao momento de ruptura paradigmática e do próprio Lipovetsky quanto à ocasião na qual esta já era notória. Da mesma maneira, conserva-se uso do termo pós-modernidade para se referir às transformações ocorridas desde então até a atualidade - exceto, claro, em citações do filósofo francês -, por se acreditar que o cenário atual nada mais é que uma confirmação e intensificação da nova mentalidade e câmbios sociais. Afinal de contas, apenas um maior distanciamento crítico e temporal possibilitará uma desejável acurácia a qualquer identificação de um possível novo paradigma. Talvez a postura mais adequada ainda seja a que Luiz Costa Lima adota já em 1991 quando, citando como exemplo a surpreendente velocidade das mudanças ainda em vigor no próprio mapa geopolítico, declara que

"parece mais acertado encarar a experiência do tempo atual como o da consciência do hiato entre as categorias analíticas herdadas de um passado ainda próximo e a urgência doutra configuração" (Lima, 1991, p. 132).

Quando se pensa na expressão contemporaneidade, o que de imediato vem à cabeça é a palavra velocidade, substantivo perfeito para sintetizar um mundo fluido e em constante 
transformação, no qual impera um regime presentista $^{3}$ facilmente observável na veiculação instantânea de informações e numa espécie de busca de prazer que não pode esperar, marca registrada da cultura do tudo já. Na verdade, nessa supervalorização do presente é inconcebível a ideia de aguardar a chegada de um futuro maravilhoso, pois o excesso se associa ao extremo numa febre consumista cujo único propósito é satisfazer os desejos imediatos, como se o aqui e agora fossem a epítome de todas as paixões e sonhos. Ou seja, o futuro é agora!

Não há dúvida de que a pós-modernidade é perpassada por uma paradoxal dinâmica de hiperconsumo desregrado em nome de uma incessante ânsia de autorrealização que não encontra término sequer na recorrente constatação da mera satisfação momentânea. Na realidade, prática quase compulsória, tendo em vista que o indivíduo é educado e seduzido pela publicidade a consumir uma gigantesca oferta de bens e serviços impregnados de promessas de felicidade e bem-estar que, por meios vários, está literalmente disponível a todas as populações do planeta 24 horas por dia. E o interessante é que, nessa caçada à porfia, a única preocupação é estar sempre atento a fim de aproveitar e adequar-se a todas as encantadoras oportunidades tão logo elas surjam (BAUMAN, 2001, p. 90-91), tal como o faz o eu lírico do poema “Ao shopping center” de José Paulo Paes: “[n]ós que por teus círculos / vagamos sem perdão / à espera (até quando?) / da Grande Liquidação" (PAES, 2001, p. 73).

Entretanto, malgrado a compulsão consumista, a intenção não é o incômodo acúmulo de bens materiais, mas sim a utilização do artigo adquirido seguida de seu descarte tão logo a prazerosa sensação de novidade se esvaeça, de modo que outro mais moderno possa suplantálo. Deveras, é precisamente a (in)capacidade de acompanhar o inesgotável suprimento de inovações tecnológicas que norteia os marcadores de índice de sucesso na sociedade de consumo. Isto é, ela determina quem são os bem-sucedidos, aqueles que se recusam a ter mais do mesmo e desfrutam a fartura de apetitosas opções do banquete consumista, e os malfadados excluídos que à míngua de recursos se veem perpetuamente atados a bens que não mais comportam o êxtase e as promessas de completude do novo (BAUMAN, 2004, p. 67$68)$.

Por conseguinte, em razão do hábito inveterado de compra desenvolvido e reforçado ao longo do último meio século, para cada celular mais sofisticado, carro mais compacto ou volumoso, televisão mais fina ou com novos recursos do tipo touchscreen, entre outros

\footnotetext{
${ }^{3}$ Cultura da imediatez cujo ritmo frenético impõe "sempre mais exigências de resultados a curto prazo, fazer mais no menor tempo possível, agir sem demora: a corrida da competição faz priorizar o urgente à custa do importante, a ação imediata à custa da reflexão, o acessório à custa do essencial" (LIPOVETSKY, 2004, p.77).
} 
exemplos na profusão coetânea de produtos, marcas e serviços, invariavelmente haverá consumidores ávidos por adquiri-los. De acordo com Lipovetsky, "o que nutre a escala consumista é indubitavelmente tanto a angústia existencial quanto o prazer associado às mudanças, o desejo de intensificar e reintensificar o cotidiano" (LIPOVETSKY, 2004, p. 79). Ou seja, a meta da corrida consumista é fugir da mesmice, daquela sufocante impressão de rotina em que o tempo termina apenas para repetir a si mesmo. É continuar sentindo a vida como nunca antes tal qual uma "fênix emocional" que renasce das cinzas da monotonia para a glória de um momento presente sempre inédito (LIPOVETSKY, 2004, p. 79-80). Todavia, assim como aponta o poema de Paes, “[d]e elevador ao céu / pela escada ao inferno / os extremos se tocam / no castigo eterno" (PAES, 2001, p. 73), esse é um processo interminável no qual a única coisa certa é a derradeira insatisfação permanente.

A essa altura é mais que claro e indubitável que a sociedade contemporânea vive sob o jugo tirânico de um padrão de felicidade que se materializa efemeramente no frenesi do consumo e que se faz ideal supremo como se sua obtenção fosse equivalente a decifrar o enigma da esfinge grega dirigida a Édipo na obra de Sófocles: "decifra-me ou te devoro" (SÓFOCLES, 2011). De fato, o pavor de ser devorado pelo marasmo da vida e de sua inerente insatisfação existencial faz com que muitos encarem o ser alegre como um décimo primeiro mandamento bíblico que demanda um empenho penoso, árduo e sem fim: "[p]elos teus círculos / vagamos sem rumo / nós almas penadas / do mundo do consumo" (PAES, 2001, p. 73).

Obviamente, uma vez que o imaginário da felicidade é acionado, começa a busca obsessiva pela invariavelmente fugidia plenitude acompanhada de inextricáveis ansiedade, insegurança e medo de vontades não cumpridas. Da mesma forma, não tarda para que se instale um verdadeiro vício de compra que se configura de inúmeras maneiras e nas mais diversas esferas do dia a dia (BAUMAN, 2001, p. 86).

Por esse motivo, não importa que tarefa se execute, cada mínima ação cotidiana se realiza conforme a praxe do comprar, e não é necessário estar em um dos incontáveis templos do consumo para tanto, como ressalta o sociólogo polonês Zygmunt Bauman, "vamos às compras na rua e em casa, no trabalho e no lazer, acordados e em sonhos. O que quer que façamos e qualquer que seja o nome que atribuamos à nossa atividade, é como ir às compras, uma atividade feita nos padrões de ir às compras" (BAUMAN, 2001, p. 87). E é justamente aí que está a inescapável problemática que se instaura quando a única escolha que não é dada ao indivíduo é refutar a compulsão à qual ele é submetido. Diante da sacralização do presente hedonista e do leque de ofertas que oferecem uma vida melhor e livre de problemas mediante 
o ter, a ele foi concedida toda a primazia em detrimento do ser. Em consequência disso e do abismo que se abre entre o revoltoso mar dos incapazes de realizar seus desejos, que por isso se sentem fracassados e infelizes, e as ilhotas dos que deleitam incansavelmente sua aventura consumista, é inevitável a precipitação da tsunami social que se observa, inter alia, na escalada dos índices de criminalidade e violência, bem como da sensação de insegurança (FUCKS, 2003, p. 79-80).

Um dos marcos principais da tentativa ensandecida de conquistar essa paradoxal felicidade é o conspícuo surto de individualismo que, para o prejuízo e desumanização do próprio consumidor, não mais deposita seu interesse em vínculos sociais genuínos. Em meio às fluidas exigências de rapidez e eficiência do reinado do efêmero, que tipificam a consagração do presente, ele se vê obrigado a sacrificar não mais apenas a sua qualidade de vida, já sobrecarregada de ansiedade e estresse, entre outras enfermidades, mas também das relações interpessoais, agora principalmente caracterizadas a um só tempo pela manutenção de um afastamento com relação ao outro e pelo empenho em sua objetificação. Segundo declara Lipovetsky:

[a]té os comportamentos individuais são pegos na engrenagem do extremo, do que são prova o frenesi consumista, o doping, os esportes radicais, os assassinos em série, as bulimias e anorexias, a obesidade, as compulsões e vícios. Delineiam-se duas tendências contraditórias. De um lado, os indivíduos, mais do que nunca, cuidam do corpo, são fanáticos por higiene e saúde, obedecem às determinações médicas e sanitárias. De outro lado, proliferam as patologias individuais, o consumo anômico, a anarquia comportamental. O hipercapitalismo se faz acompanhar de um hiperindividualismo distanciado, regulador de si mesmo, mas ora prudente e calculista, ora desregrado, desequilibrado e caótico. No universo funcional da técnica, acumulam-se os comportamentos disfuncionais. O hiperindividualismo coincide não apenas com a internalização do modelo do homo oeconomicus que persegue a maximização de seus ganhos na maioria das esferas da vida (escola, sexualidade, procriação, religião, política, sindicalismo), mas também com a desestruturação de antigas formas de regulação social dos comportamentos, junto a uma maré montante de patologias, distúrbios e excessos comportamentais. Por meio de suas operações de normatização técnica e desligação social, a era hipermoderna produz num só movimento a ordem e a desordem, a independência e a dependência subjetiva, a moderação e a imoderação (LIPOVETSKY, 2004, p. 55-56).

Prova disso é a cada vez maior substituição do tradicional tête-à-tête ${ }^{4}$ para o estabelecimento e manutenção de tratos sociais pelos contatos virtuais no ciberespaço. Embora o evento registrado seja o de uma eventual conversa ao celular, a ilustração de Bauman em seu livro Amor líquido de como a realidade concreta está sendo substituída pelo mundo virtual não só é formidável, mas é perfeitamente análoga ao que ocorre entre os surfistas da net nos dias de hoje (BAUMAN, 2004, p. 83). Afinal de contas, não é nenhuma

\footnotetext{
${ }^{4}$ Conversa privada de dois indivíduos.
} 
surpresa que os celulares mais modernos também são ferramentas próprias para navegar no ambiente virtual. A despeito da expectativa que se cria ao se testemunhar fortuitamente uma comunicação via celular ou webcam, seja no ônibus, na sala de aula ou num cybercafé, de que ela representa uma prévia para algo mais concreto, o fato é que tais interações já carregam em si todo um status de realidade material. Em termos de experiência sensorial ela é real. E, não raramente, apenas antecede as mais frias ou indiferentes relações pessoais quando há o derradeiro encontro entre os interlocutores.

Outrossim, no que concerne às relações virtuais, já tão fundamentais na vida social e presença marcante no imaginário das pessoas, e normalmente travadas em salas de bate-papo, sites de buscas, comunidades virtuais e afins, o olhar para si é persistente. Tudo que se quer é manter um ritmo constante de relações - quanto mais, melhor - que sejam fugazes e sem muito compromisso, algo como pelo menos um amor por semana, e que minimamente garantam a esperança de um romantismo intenso e repleto de satisfação. Em geral, o outro não passa de mero objeto nessa história. Tal como evidencia Bauman com relação a essa paradoxal proximidade virtual: "“[a] distância não é obstáculo para se entrar em contato mas entrar em contato não é obstáculo para se permanecer à parte" (BAUMAN, 2004, p. 82, grifo do autor). Portanto, em oposição à contiguidade topográfica de outrora, única escolha para aqueles que quisessem estabelecer e dar continuidade a intercâmbios sociais, e que certamente requeria mais tempo e esforço, sem contar os inconvenientes de possíveis confusões, traumas e sofrimentos por ocasião da ruptura de tais laços, atualmente a moda é estar conectado virtualmente, o que sem dúvida apresenta risco quase zero e custa muito menos em todos os sentidos de acordo com a escala de valores da era pós-moderna.

Se há algo intrínseco aos relacionamentos online é a sensação de segurança e a certeza de que uma vez que a paquera, amizade colorida, namoro, ou seja qual for o tipo de vínculo, não se configure mais como uma fonte de prazeres inéditos, eles podem ser detonados sem a mínima preocupação por simplesmente bloquear ou até mesmo excluir a persona non grata do domínio virtual do consumidor de sensações. E o melhor é que o indivíduo-cliente poderá voltar à caça, pois sempre haverá incontáveis itens no cardápio a serem saboreados (BAUMAN, 2004, p. 85).

O curioso é que, por mais exagerado que possa parecer, as experiências vividas através de contatos virtuais são bem concretas, dado que ocorrem em "um sistema em que a realidade em si está imersa por completo num ambiente de imagens virtuais, onde os símbolos não são metáforas, mas abarcam a experiência real" (FUCKS, 2003, p. 78). E apesar de aparentemente inócuas, elas possuem um lado nocivo velado que se torna manifesto a partir do instante que 
se tornam pedra de toque "pela qual todos os outros pretendentes ao status de realidade devem se avaliar e ser julgados" (BAUMAN, 2004, p. 83). Para o sujeito, o norte existencial deixa de ser as situações vividas no mundo concreto cotidiano, dando espaço à hiper-realidade, uma verdade que se autointitula "mais real que o real" (FERNANDES, 2005, p. 376-77). Não é à toa que Stanley Fish parodia o livro de João 8:32 a fim de retratar essa particular desreferencialidade da cultura contemporânea: “[s]abereis que a verdade não é o que parece, e essa verdade vos libertará" (FISH, 1990, p. 448, grifo do autor).

De mais a mais, outro campo no qual se percebe claramente a tendência individualista do sujeito pós-moderno é o sexual. Deveras, uma das razões de suas investidas no universo virtual tem exatamente a ver com o propósito de dar solução a sua miséria sexual. E não somente por meio do tão conhecido sexo virtual, mas também pela concreta união física dos corpos. Consoante Bauman, "[a]s agonias atuais do homo sexualis são as mesmas do homo consumens. Elas nasceram juntas. Se um dia se forem, marcharão ombro a ombro" (BAUMAN, 2004, p. 67). Logo, da mesma maneira que se busca plenitude pela aquisição de bens materiais, tenta-se também obtê-la na reificação do outro com quem se pode conseguir o clímax orgástico. Obviamente, como se pode facilmente inferir mediante o que foi visto até aqui, em ambos os casos a satisfação é efêmera, e quiçá a percepção da brevidade do prazer seja maior ainda no caso do encontro sexual tendo em conta que ela só permanece durante o ínfimo instante do gozo.

A busca de completude através do sexo casual se explica pelo simples fato de o indivíduo humano possuir uma natureza imanentemente social. Em outras palavras, é mister o convívio com seus pares, assim como anelar a fusão com o outro para escapar da solidão à qual está sujeito ou teme sofrer (BAUMAN, 2004, p. 55). Contudo, de um modo geral, tudo indica que o sujeito pós-moderno está fadado a permanecer irrealizado nesse empreendimento tão repleto de ansiedade. Primeiro porque, tal qual o típico consumista, sempre tem a impressão de que há algo mais a experimentar, e que pôr termo à corrida pela felicidade será como condenar-se à eterna incerteza. Segundo, devido ao tipo de união que almeja, visto que esta não está calcada nem no amor, nem no compromisso, respeito e preocupação com o bemestar do outro que tipificam a fusão genuína. Ao contrário, a união sexual que se procura é de curta duração e, como é de se esperar, confirma e até mesmo ressalta o caráter ilusório e frustrante da conexão que se estabelece (BAUMAN, 2004, p. 62-63; 73-74).

A propósito, outra propalada modalidade de prática sexual que tem estado em voga e cuja essência não difere muito do quadro supracitado ocorre nos clubes de swing, onde, em comum acordo, casais intercambiam cônjuges para sair da mesmice e provar pratos distintos. 
Uma vez mais, porém, tampouco a fuga passageira dos grilhões do casamento provou ser eficaz em termos de prover a um só tempo uma legítima sensação de plenitude e alívio quanto aos riscos, incertezas e possíveis importunos atrelados a qualquer aventura sexual (BAUMAN, 2004, p. 71). De fato, o mais provável é que os mesmos fatores que motivaram a perseguição dessa felicidade paradoxal persistam, bem como os recorrentes vazio e questionamentos que decerto se seguem: “[s]erá [mesmo] que os anseios irrealizados, as frustrações amorosas, os temores de ficar só e de se ferir, a hipocrisia e a culpa são deixados para trás depois de uma visita ao clube?” (BAUMAN, 2004, p. 72). Em concordância com as proposições aqui esboçadas e lançando luz adicional sobre este aspecto do comportamento humano na pós-modernidade, Lipovetsky declara que:

\begin{abstract}
[s]er incompleto, incapaz de se bastar a si próprio, o ser humano tem necessidade do outro para conhecer a felicidade. No entanto, por depender da relação com o outro, o indivíduo está inevitavelmente condenado às decepções e às mágoas da vida. Uma vez que preciso dos outros para ser plenamente feliz, a minha felicidade é necessariamente fugaz e instável. Sem o outro não sou nada; com o outro, estou à sua mercê: a felicidade à qual o homem pode aceder só pode ser uma 'felicidade frágil'. A lição é reveladora: como não podemos ser felizes sozinhos, não somos senhores da felicidade. É algo que nos 'acontece' ou nos abandona, e que em larga medida escapa ao nosso controlo [sic]; é, por excelência, aquilo que não possuímos. A influência do outro na nossa felicidade é considerável, e dispomos apenas de um fraco poder para controlar o seu curso. Infelizmente, a experiência da felicidade é efémera [sic] (LIPOVETSKY, 2006, p. 301-302, grifo meu).
\end{abstract}

Sem embargo, a despeito da liquidez pós-moderna na qual nada é sólido e tudo é descartável, ainda há laços que são irrevogáveis, tais como os de pai e mãe. Por isso mesmo a atitude consumista neste caso merece especial atenção, já que não é o prazer parental que orienta a decisão de assumir tal compromisso, mas sim o transitório desejo de consumo diante das opções. Conforme Bauman esclarece, "[e]sta é uma época em que um filho é, acima de tudo, um objeto de consumo emocional" (BAUMAN, 2004, p. 59). E as escolhas são inúmeras: dentre outras, pode-se optar pela adoção na qual, não é novidade, a seleção é orientada pela boa aparência das crianças fenotipicamente sortudas por atender aos critérios de mercado. Ou então eleger no menu de um banco de espermas o garanhão ideal que dará boa cria. E com certeza não tarda para que seja lugar-comum determinar geneticamente os traços do novo ser ainda quando embrião. Finalmente, acrescente-se à lista de opções a decisão de quando e como fazer o parto (BAUMAN, 2004, p. 57-58).

Entretanto, não importa o quão experiente se creia o consumidor, este é sem dúvida o tipo de aquisição que mais provoca angústia e estresse em consequência dos temores especialmente inerentes a esse campo de perigos inexplorados. Prova disso são os frequentes 
casos de depressão pós-parto e crises conjugais que não poucas vezes sucedem os nascimentos. Além do mais, ceder a este impulso vai de encontro à noção de consumo prudente, pois os custos não são apenas monetários. Sem sombra de dúvidas, haverá também as incomensuráveis dores do autossacrifício em favor de outrem que implicará o encerramento por tempo indefinido das tentativas de comprazer às necessidades consumistas individuais (BAUMAN, 2004, p. 60).

Por conseguinte, em oposição ao período que precede a pós-modernidade, quando o consumo era sinônimo de poder econômico e marca de status pessoal, hoje a lógica do consumo é tipificada por seu caráter subjetivo e emocional facilmente observado na interminável procura individualista da felicidade (SILVA, 2009, p. 298). Na realidade, o fato é que sob estes novos parâmetros o consumo tem assumido cada vez mais uma função identitária (SILVA, 2009, p. 298), como ilustra magistralmente o eu lírico na abertura de "Eu, etiqueta", escrito pelo poeta visionário Carlos Drummond de Andrade:

[e]m minha calça está grudado um nome / que não é meu de batismo ou de cartório / um nome... estranho. / Meu blusão traz lembrete de bebida / que jamais pus na boca, nessa vida. / Em minha camiseta, a marca de cigarro / que não fumo, até hoje não fumei. / Minhas meias falam de produto / que nunca experimentei / mas são comunicados a meus pés. / Meu tênis é proclama colorido / De alguma coisa não provada/ por este provador de longa idade. / Meu lenço, meu relógio, meu chaveiro, / minha gravata e cinto e escova e pente, / meu copo, minha xícara, / minha toalha de banho e sabonete, / meu isso, meu aquilo (ANDRADE, 1995, p. 8586).

Segundo assinala o poema com referência à sociedade de consumo, que ao que tudo indica estava significativamente consolidada à época de sua escritura, além desta impor ao indivíduo uma identidade não necessariamente correspondente àquela que ecoa em seu âmago, o como ele se vê, sente e identifica, atribui-lhe também uma experiência que, ainda que não seja a sua, se estende a todas as esferas de sua existência. Com efeito, tal como afirma Paul du Gay (2002, p. 153), tendo em conta uma perspectiva mais ampla, "dado que qualquer identidade é basicamente relacional em termos de suas condições de existência, qualquer mudança na última certamente afetará a primeira", as identidades contemporâneas são incessantemente (des)construídas de acordo com os ditames da fluidez pós-moderna. Destarte, elas podem ser (re)fabricadas ou até mesmo compradas consoante as imposições da sociedade de consumo ou então continuarem em permanente rearticulação a fim de não ceder à lógica consumista do contexto coetâneo e a sua falaciosa e sedutora versão de felicidade.

Embora não raramente se conceba a identidade como sendo algo fixo, coerente e estável (BAUMAN, 2001, p. 97), ela varia de acordo com as circunstâncias, assim como com 
a conjuntura histórica e sociocultural, tal como atesta Chris Barker: "[a]s identidades são construções discursivas que mudam seus significados conforme o tempo, lugar e uso" (BARKER, 2008, p. 217). Tampouco corresponde a identidade do sujeito contemporâneo ao fantasioso monólito que muitas vezes a representa. Muito ao contrário, fragmentada e múltipla, por vezes ela comporta até mesmo identidades contraditórias (BARKER, 2008, p. 220).

Por essa razão, a cômoda noção de uma identidade completa em si mesma não passa de uma mera ilusão que desconsidera a crise na qual a identidade do sujeito pós-moderno se encontra, e que faz dela um tema altamente discutido, assim como o seu processo perpétuo de formação caracterizado principalmente por uma inquestionável abertura a novas (re)significações e (re)contextualizações (HALL, 2002, p. 2). Deveras, Stuart Hall retrata o sujeito pós-moderno como sendo

conceptualizado como não tendo uma identidade fixa, essencial ou permanente. A identidade torna-se uma 'celebração móvel': formada e transformada continuamente em relação às formas pelas quais somos representados ou interpelados nos sistemas culturais que nos rodeiam. É definida historicamente, e não biologicamente. $O$ sujeito assume identidades diferentes em diferentes momentos, identidades que não são unificadas ao redor de um 'eu' coerente (HALL, 2005, p. 12-13).

Não é de surpreender, portanto, que diante da liquidificação das sólidas certezas de outrora que perpassa a pós-modernidade o indivíduo eventualmente sinta uma sensação de estar perdendo o sentido da vida, da própria identidade, e que por sua falta de convicções se torne presa fácil das inúmeras artimanhas disponíveis para despertar e manter em seu imaginário a sensação de que o consumo desenfreado é o único porto seguro neste mar revoltose de dúvidas, medos e incertezas. Esse processo de capitulação é tão luzente em "Eu, etiqueta" como nos anúncios das lojas, televisão e revistas de consumo:

desde a cabeça ao bico dos sapatos, / são mensagens, / letras falantes, / gritos visuais, / ordens de uso, abuso, reincidência, / costume, hábito, premência, / indispensabilidade, / e fazem de mim homem-anúncio itinerante, / escravo da matéria anunciada. / Estou, estou na moda (ANDRADE, 1995, p. 86, grifo meu).

Curiosamente, por mais que prolongue sua vida, transforme o seu físico, supra toda e qualquer de suas aparentes necessidades emocionais, tudo quase sempre mediante o consumo, a volatilidade provocada pela desestabilização do eu impede que o sujeito pós-moderno se sinta realizado e motivado a se empenhar continuamente por mais e mais emoções. Como resultado, em consonância com a declaração de Lipovetsky de que 
"[q]uanto mais o indivíduo é socialmente cambiante, mais surgem manifestações de esgotamentos e 'panes' subjetivas. Quanto mais ele quer viver intensa e livremente, mais se acumulam os sinais do peso de viver" (Lipovetsky, 2004, p. 84),

verifica-se em "Ao shopping center” o quanto padece o eu lírico em sua infindável jornada consumista: "Cada loja é um novo / prego em nossa cruz / Por mais que compremos / estamos sempre nus" (PAES, 2001, p. 73). Da mesma maneira, é patente o quanto o indivíduo se autoanula em termos identitários quando sucumbe ao processo homogeneizador da sociedade de consumo e paradoxalmente encontra nisso a tão desejada satisfação, mesmo que efêmera. Desnecessário dizer que o único interesse nesse caso é que o enxame de clientes esteja atento ao que está na ordem do dia e possa, por meio de aquisição, trocar de identidade tão facilmente como se muda de roupa, tal como descrito no poema de Drummond:

[é] doce andar na moda, ainda que a moda / seja negar minha identidade, / trocá-la por mil, açambarcando / todas as marcas registradas, / todos os logotipos do mercado. / Com que inocência demito-me de ser / eu que antes era e me sabia / tão diverso de outros, tão mim mesmo, / ser pensante sentinte e solitário / com outros seres diversos e conscientes/ de sua humana, invencível condição. / Agora sou anúncio / ora vulgar ora bizarro, / em língua nacional ou em qualquer língua / (qualquer, principalmente). / E nisto me comprazo, tiro glória/ de minha anulação. (ANDRADE, 1995, p. 86).

Uma vez mais, como se pode averiguar nesse trecho, o eu lírico parece ironicamente demonstrar como o consumidor normalmente não se sente nada incômodo com a ideia de anular-se, invalidar a sua identidade para atender aos desígnios da moda. De fato, o indivíduo contemporâneo se deleita com a possibilidade de “ir às compras' no supermercado das identidades" (BAUMAN, 2001, p. 97-98) e gozar das incontáveis opções que o esperam para que possa realizar suas fantasias identitárias e descartá-las quando o convier. E o interessante é que o faz conquanto essa atividade signifique, no fim das contas, a sua própria reificação, como se pode ver na conclusão de "Eu, etiqueta": “[p]or me ostentar assim, tão orgulhoso / de ser não eu, mas artigo industrial, / peço que meu nome retifiquem. / Já não me convém o título de homem. / Meu nome novo é coisa. / Eu sou a coisa, coisamente" (ANDRADE, 1995, p. 87).

Não obstante, por mais paradoxal que essa dinâmica possa parecer, ela nada mais é que o resultado de todo um trabalho e investimentos maciços por parte dos fornecedores de bens de consumo que apostam na produção de um comprador voraz, cujo desejo é despertado e devidamente direcionado, que vê no mar de impessoalidade formado por ondas de consumidores de um shopping center, por exemplo, a única solução para todos os males que o 
afligem no presente ou possam vir a afligi-lo no futuro (BAUMAN, 2001, p. 88-89; 2004, p. 89). Novamente, volta-se à dimensão temporal, que, a essa altura, merece uma atenção mais detida.

Malgrado as tão aguardadas bênçãos futuristas semeadas e propaladas pela rajada de otimismo da modernidade quando a percepção do porvir era outra e se

"encara[va] a história como um progresso contínuo e ilimitado no sentido da justiça, da liberdade e da felicidade. A história universal tem um propósito: o progresso infinito da humanidade, o caminho desta para a felicidade plena" (Lipovetsky, 2006, p. 286),

as inúmeras tragédias que assolaram a humanidade ao longo do século $\mathrm{XX}$, muitas delas em nome desse suposto progresso, fizeram com que os ventos mudassem de direção e a confiança no futuro fraquejasse. $\mathrm{Na}$ verdade, tornou-se dominante uma noção do porvir como algo indeterminado e problemático que se fez solo fértil para as visões pessimistas que viam todo e qualquer avanço da tecnociência como algo negativo (Lipovetsky, 2006, p. 287).

Consoante já analisado, é justamente essa descrença no futuro repleto de incertezas e riscos que contrai o tempo numa lógica urgentista na qual a imposição do atual e das satisfações imediatas confirmam a consagração do presente. Segundo Fucks,

“[a]s concepções de espaço e tempo não são mais absolutas. O tempo cronológico da modernidade se transforma no tempo intemporal reduzido ao instante: é a cultura do efêmero, da virtualidade do real" (FUCKS, 2003, p. 78).

Isto é, as promessas do futuro são substituídas por um regime presentista que atribui suma importância à questão do aproveitamento máximo do fator tempo (LIPOVETSKY, 2004, p. 75). No entanto, ainda há uma pendência não examinada até aqui: onde está o passado nessa história?

Eis aí outro paradoxo do universo pós-moderno, porquanto o reinado do presente na sociedade imediatista não é absoluto, mas dialoga frequentemente com o passado (LIPOVETSKY, 2004, p. 85). Todavia, essa valorização do pretérito está longe de ser inocente, visto que o gosto pelas coisas de antanho é provocado mediante uma "reciclagem e retradução de memória com fins econômicos, emocionais e identitários” (LIPOVETSKY, 2004, p. 91). Em outras palavras, a tradicional contemplação solene do legado de outrora cedeu lugar a uma celebração deste mormente caracterizada por um aspecto frívolo e efêmero em consequência da mercantilização da cultura e da geração e fomento da indústria do patrimônio histórico. A título de exemplo, Lipovetsky destaca que agora 
“[o]s museus encenam espetáculos históricos, e os sítios arqueológicos, reconstituições em simulação virtual: o 'turismo da memória' é sucesso entre as massas. As obras do passado [...] são [...] 'devoradas' em alguns segundos" (LIPOVETSKY, 2004, p. 88).

De mais a mais, essa mania do antigo comporta uma dimensão nostálgica na qual se vende o passado através do lançamento de produtos de cunho saudosista, que, não poucas vezes, também é explorado pelas empresas que, como estratégia de marketing, tentam associar seus produtos a um suposto passado comum compartilhado tanto pela empresa quanto pela sociedade a fim de gerar identificação (ANDREONI, 2011, p. 176-77). Logo, tal como observa Lipovetsky com relação a esse revivescimento do passado, esse é

“[u]m fenômeno indissociavelmente pós- e hipermoderno. 'Pós' porque se volta para o antigo. 'Hiper' porque doravante há consumo comercial da relação com o tempo, pois a expansão da lógica mercantil invade o território da memória" (LIPOVETSKY, 2004, p. 89).

Entretanto, apesar dos incontáveis avanços tecnológicos capazes de prover os mais diversos prazeres e satisfações, a única coisa certa são os crescentes índices de insegurança. Embora a princípio a atitude frívola e o descaso com o futuro tenham predominado na pósmodernidade, Lipovetsky acredita que cada vez mais o tempo presente é inundado por uma onda de receios, ansiedade e medo provenientes, inter alia, das ações de terrorismo, sobretudo os que sucedem o 11 de setembro, epidemias capazes de se proliferar por todo o planeta em poucos dias como a gripe aviária e, mais recentemente, o Covid- $19^{5}$, as lutas sociais que ressoam nos quatro cantos do mundo pelas mais variadas razões, como as manifestações que sucederam ao propalado assassinato de George Floyd ${ }^{6}$ e, não menos importante, o temor de uma hecatombe ambiental que se configura diariamente, por exemplo, no desmatamento descontrolado e no derretimento das geleiras em resultado do aquecimento global, e torna imperativo pôr freios à degradação do planeta (LIPOVETSKY, 2004, p. 63-64). Contudo, de acordo com o otimista filósofo francês:

[a]nte as ameaças da poluição atmosférica, da mudança climática, da erosão da biodiversidade, da contaminação dos solos, afirmam-se as ideias de

\footnotetext{
${ }^{5}$ Doença infecciosa causada por um coronavírus recém-descoberto que ceifou a vida de mais de 1.200.000 pessoas no mundo entre 31 de dezembro de 2019 e o fim de outubro de 2020.

${ }^{6}$ Afro-americano assassinado em Minneapolis, EUA, no dia 25 de maio de 2020, por um policial branco que ajoelhou em seu pescoço por longos 8 minutos e 46 segundos apesar de repetidas súplicas "eu não consigo respirar".
} 


\begin{abstract}
'desenvolvimento sustentável' e de ecologia industrial, com o encargo de transmitir um ambiente viável às gerações que nos sucederem. [...]

Sem dúvida, os interesses econômicos imediatos têm precedência sobre a atenção para com as gerações futuras. Durante esse espetáculo de protestos e de chamamentos virtuosos, a destruição do meio ambiente continua: o máximo de apelos à responsabilidade de todos, o mínimo de ações públicas. Mas o fato é que as preocupações referentes ao futuro planetário estão bem vivas; elas habitam e alertam permanentemente a consciência do presente, alimentando as controvérsias públicas, solicitando medidas de proteção para o patrimônio natural. O presente total da rentabilidade imediata pode dominar, mas não continuará assim indefinidamente. Mesmo que o ecodesenvolvimento ainda esteja longe de dispor dos meios técnicos e sistemas reguladores dos quais necessita, ele já começa, aqui e ali, a alterar certas práticas. No amanhã, essa dinâmica deve ampliar-se. É pouco provável que a consciência e as limitações de longo prazo não produzam efeito; elas transformarão tanto as práticas presentistas quanto os modos de vida e de desenvolvimento (LIPOVETSKY, 2004, p. 68-70).
\end{abstract}

$\mathrm{Na}$ verdade, essa percepção de que a moral não foi totalmente substituída pelo egoísmo é também compartilhada por Bauman. Conforme descreve o sociólogo polonês, a despeito de todos os esforços engendrados pela economia de mercado, persiste uma significativa parcela da sociedade que pratica um tipo distinto de economia, a qual o sociólogo britânico Albert Henry Halsey denomina 'economia moral'. Ela seria principalmente tipificada pelo "compartilhamento familiar de bens e serviços, a ajuda entre vizinhos, a cooperação entre amigos: todos os motivos, impulsos e atos com que se costuram os vínculos e compromissos duradouros entre os seres humanos" (BAUMAN, 2004, p. 89). O curioso é que é exatamente a persistência dessa economia alternativa, tal qual um quebra-mar, que mitiga o poder destruidor da tsunami social que se verifica em crescentes números de criminalidade, violência e da sensação de insegurança inquestionavelmente impulsionados a cada nova série de abalos sísmicos provocados pela economia de mercado com o propósito de alimentar sua cultura neofílica e hedonista. Consoante corrobora Bauman: "[n]ão fosse pela intervenção corretiva, lenitiva, suavizante e compensadora da economia moral, a economia de mercado exporia seu impulso autodestrutivo" (BAUMAN, 2004, p. 90).

Desnecessário dizer, portanto, que essa solidariedade em que prevalece a amizade e as parcerias humanas inverte a lógica consumista e dá primazia à ação coletiva em detrimento das felicidades privadas. Ademais, é ela que explica a expressiva participação de uma substancial parcela da população, pertencente a diversos segmentos sociais, nas mais variadas formas de demonstração de responsabilidade social para com os desfavorecidos da sociedade de consumo, bem como os vitimados por catástrofes naturais, epidemias e outras mazelas da vida. Norteados por suas convicções morais, tais indivíduos costumam praticar sua compaixão por meio de trabalho voluntário, doações, e inúmeras outras atividades de caráter altruísta. Assim sendo, tal como afirma Lipovetsky com referência a este aspecto positivo da 
pós-modernidade, “[a] verdade é que o nosso tempo não se caracteriza tanto pela depreciação de todos os valores como por uma revivescência da interrogação moral ligada ao esmorecimento da influência do político e dos grandes sistemas de sentido" (LIPOVETSKY, 2006, p. 307).

Num plano mundial, embora seja inegável o aspecto perverso da chamada globalização, não há como negar suas contribuições para a transformação das linhas divisoras do passado em fronteiras de cooperação que, além de promover aproximações mundiais, também têm feito com que o comunitarismo internacional esteja, quiçá, mais em alta que nunca. Com efeito, não são poucos os que adotam uma atitude crítica e afirmam que por detrás da generosa imagem de uma cultura planetária democrática há uma intenção velada de suprimir especificidades locais. Isto é, a globalização seria uma nova modalidade de imperialismo econômico, político e cultural cuja expansão se basearia num discurso dissimulado que apregoaria uma fraternidade transnacional homogênea e hegemônica sem ter em conta as incontáveis diferenças entre os membros. Como se pode facilmente inferir, tal prática seria prejudicial aos interesses dos membros mais vulneráveis da arena global (JOBIM, 2002, p. 38, 54), já que, como ressaltam Ashcroft, Griffiths e Tiffin: “a globalização nem impacta do mesmo modo, com a mesma intensidade, nem beneficia igualmente comunidades diferentes" (ASHCROFT; GRIFFITHS; TIFFIN: 2002, p. 111).

Seja como for, da mesma maneira é impossível deixar de reconhecer que a possibilidade de que hoje gozam comunidades locais oprimidas e grupos marginalizados de se apropriar de estratégias de representação, organização e mudança social que acompanham os fluxos culturais globais e igualmente influenciá-los é fortalecedoramente ímpar (ASHCROFT; GRIFFITHS; TIFFIN: 2002, p. 113-14). Segundo observam Philip Smith e Alexander Riley acerca da globalização:

\begin{abstract}
o processo abriu espaço para a periferia ter uma voz, com o poder monolítico e a autoridade do centro sujeitos a questionamentos provenientes de múltiplos centros rivais. A imagem aqui é de um tumulto de vozes que se prolifera interminavelmente, sendo o único ponto comum a desestabilização de hierarquias estabelecidas e pontos de referência, bem como asserções de diferença. Neste contexto, os valores culturais ocidentais são relativizados como apenas uma outra forma local que foi posta em contato com outras por meio da globalização (SMITH; RILEY, 2009, p. 225).
\end{abstract}

Por conseguinte, ainda que seja indiscutível o risco de possíveis novas assimetrias de poder mundialmente geradas pela globalização, não se pode rejeitar o seu aspecto positivo patente nesta nova realidade na qual o global e o local reorganizam e moldam um ao outro de um modo mais democrático e com um grau nunca observado de integração e interconexão 
entre inúmeros lugares, por mais longínquos que sejam, cujas culturas se encontram, se justapõem e se combinam no tempo e no espaço. Além do mais, é precisamente essa face da globalização que propicia um contexto favorável para as múltiplas articulações comunitárias que marcam presença no cenário mundial. De acordo com Benjamin Abdala,

[b]ons exemplos dessas ações todos conhecemos: articulações que hoje se intensificam entre setores politicamente não hegemônicos, como os movimentos supranacionais de caráter étnico, ecológicos, de gêneros, de defesa das crianças, etc. Ou intervenções mais pontuais, como a do Timor Leste, que mobilizaram não apenas, mas sobretudo[,] os países de língua portuguesa, logrando sensibilizar a opinião pública dos países centrais (ABDALA JUNIOR, 2002, p. 15).

Deveras, uma vez que os espartilhos dos estados nacionais se afrouxam e a noção de Benedict Anderson de comunidade imaginada se torna mais abrangente, decerto ganha espaço e força uma perspectiva de "identidade coletiva, uma nova visão compartilhada, que tende a ser supranacional" (ABDALA JUNIOR, 2002, p. 17).

Em conclusão, diante dos vários pontos analisados neste ensaio, a única coisa incontestável é que o estágio atual da pós-modernidade é conspicuamente distinto do de sua fase incipiente dado o acelerado ritmo de suas transformações. Da mesma maneira, o futuro da pós-modernidade está em aberto e só o tempo dirá se as previsões otimistas que começam a pulular aqui e ali se confirmarão. Conforme defende Fucks:

“[c]omo estamos mergulhados nesta sociedade [pós-moderna] e seu advento é recente, nos faltam perspectivas históricas para uma reflexão, sendo preciso mais distanciamento [crítico e temporal] e pesquisas sobre inúmeras questões em aberto" (FUCKS, 2003, p. 82).

Outrossim, é fundamental atentar que o preço pago pela caça desmesurada à felicidade consumista de satisfações passageiras não somente tem sido os diversos males subjetivos listados ao longo do ensaio, mas também o comprometimento da biosfera e dos limitados recursos naturais. Consoante assinala Lipovetsky com respeito aos exageros da cultura hedonista e sua urgência de prazeres:

"indiferente às consequências a longo prazo, a corrida frenética à produção e às satisfações materiais é denunciada, cada vez mais, como um processo louco que origina a poluição do ambiente, a erosão da biodiversidade, o aquecimento global" (LIPOVETSKY, 2006, p. 291).

Curiosamente, porém, é justamente a necessidade premente de câmbio que esse quadro desperta que promove transformações sociais e ambientais, tais como as sugeridas por 
Fucks: "[p]odem ser introduzidos indicadores qualitativos, baseados em fatores como poluição atmosférica, poluição sonora, segurança e conforto, níveis de estresse, geração de emprego e lazer" (FUCKS, 2003, p. 96).

Efetivamente, Lipovetsky acredita que já são perceptíveis alguns indícios que sinalizam uma mudança de comportamento no sentido de reorientar a sociedade do consumo e, assim, reduzir as desigualdades sociais para dar início a um efetivo desenvolvimento sustentável. Como já foi destacado, além das iniciativas solidárias norteadas por um tipo de economia perpassada por sentimentos morais que ultrapassam as fronteiras dos estados nacionais, segundo o filósofo francês, é significativo o número de alterconsumidores que não aceitam meramente ser vítimas das práticas de mercado, mas buscam por seus próprios meios realizar um consumo consciente, alternativo e com o mínimo de impacto ambiental (LIPOVETSKY, 2006, p. 294-95).

Finalmente, embora a tão celebrada felicidade seja o ideal mor da sociedade de consumo e de seus vorazes consumidores, a verdade é que o sujeito pós-moderno não está feliz. Prova disso é que paradoxalmente cada vez mais abundam os comprimidos para manter a alegria, a esperança, e até mesmo a libido, o apetite e o sono (SILVA, 2009, p. 299). De fato, esquece-se que antes de qualquer esforço ou tentativa em prol desse bem maior invariavelmente haverá um entrave que independe da vontade humana e sobre o qual não temos nenhum controle, chamado inconsciente. Por essa razão, a busca consciente da felicidade não passa de uma ilusão, tendo em vista que está muito além da capacidade de qualquer indivíduo determinar precisamente o método ou forma que ensejará a tão cobiçada solução desse enigma que permanecerá "fugitivo, imprevisível e insolúvel” (LIPOVETSKY, 2006, p. 302-303). Assim sendo, talvez a melhor atitude para com este inestimável ideal de plenitude que é a felicidade ainda seja a atemporal noção que se faz fio condutor do poema "Eternity”, escrito pelo poeta romântico inglês William Blake: "[a]quele que amarra a si mesmo uma alegria / A vida alada destrói; / Mas aquele que beija a alegria enquanto ela voa / Vive na aurora da eternidade" (BLAKE, 1966, p. 179).

\section{Referências}

ABDALA JUNIOR, B. Fronteiras múltiplas e hibridismo cultural: novas perspectivas iberoafro-americanas. In: SCARPELLI, Marli Fantini; DUARTE, Eduardo de Assis. (Org.). Poéticas da Diversidade. Belo Horizonte: UFMG/FALE/Pós-lit, 2002. p. 15-35.

ANDRADE, C. D. Eu, etiqueta. In: . Corpo. Rio de Janeiro: Record, 1995. p. 85-87. 
ANDREONI, R. Museu, memória e poder. Questão, Porto Alegre, v. 17, n. 2, p. 167-179, jul./dez. 2011.

ASHCROFT, B.; GRIFFITHS, G.; TIFFIN, H. (Eds.). Post-Colonial Studies: The Key Concepts. London: Routledge, 2002. 275 p.

BARKER, C. Cultural Studies. London: Sage, 2008. 525 p.

BAUMAN, Z. Dentro e fora da caixa de ferramentas da sociabilidade. In: Amor líquido. Tradução de Carlos Alberto Medeiros. Rio de Janeiro: Jorge Zahar Editor, 2004. p. 55-96.

Individualidade. In: Modernidade líquida. Tradução de Plínio Dentzien. Rio de Janeiro: Jorge Zahar Editor, 2001. p. 64-106.

BÍBLIA. Português. Tradução do Novo Mundo das Escrituras Sagradas. Cesário Lange: Associação Torre de Vigia de Bíblias e Tratados, 1986. 1662 p.

BLAKE, W. Complete Writings with Variant Readings. London: Oxford Press, 1966. 944 p.

DU GAY, P. Organizing Identity: Entrepreneurial Governance and Public Management. In: HALL, S.; (Eds.). Questions of Cultural Identity. London: Sage Publications, 2002. p. 151-69.

FERNANDES, G. M. Pós-moderno. In: FIGUEIREDO, Eurídice. (Org.). Conceitos de literatura e cultura. Juiz de Fora: UFJF, 2005. p. 365-91.

FISH, S. E. Doing What Comes Naturally: Change, Rhetoric, and the Practice of Theory in Literary and Legal Studies. London: Duke University Press, 1990. 613 p.

FUCKS, S. A sociedade do conhecimento. Tempo Brasileiro, Rio de Janeiro, n. 152, p. 75101, jan./mar. 2003.

HALL, S. A identidade cultural na pós-modernidade. Tradução de Tomaz Tadeu da Silva e Guacira Lopes Louro. Rio de Janeiro: DP\&A, 2005. 102 p.

. Introduction: Who Needs 'Identity'? In: ; DU GAY, P. (Eds.). Questions of Cultural Identity. London: Sage Publications, 2002. p. 1-17.

JOBIM, J. L. Nacionalismo e Globalização. In: Formas da teoria: sentidos, conceitos, políticas e campos de força nos estudos literários. Rio de Janeiro: Caetés, 2002. p. 19-66.

LIMA, L. C. Pós-modernidade: contraponto tropical. In: Pensando nos trópicos. Rio de Janeiro: Rocco, 1991. p. 119-137.

LIPOVETSKY, G. Homo felix: grandeza e miséria de uma utopia. In: A felicidade paradoxal: ensaio sobre a sociedade do hiperconsumo. Tradução de Maria Lúcia Machado. Lisboa: Edições 70, 2006. p. 285-317.

Tempo contra tempo, ou a sociedade hipermoderna. In: CHARLES, Sébastien; Os tempos hipermodernos. São Paulo: Barcarolla, 2004. p. 49-103. 
PAES, J. P. Ao shopping center. In: . Prosas seguidas de odes mínimas. São Paulo:

Companhia das Letras, 2001. 73 p.

SEABROOK, J. The Leisure Society. Oxford: Blackwell, 1988. 195 p.

SILVA, E. C. Interminável busca da felicidade. Mediações, v. 14, n. 1, p. 297-299, 2009.

SMITH, P.; RILEY, A. The Cultural Analysis of Postmodernism and Postmodernity. In: 207-27. Cultural Theory: An Introduction. Malden: Blackwell Publishing, 2009. p.

SÓFOCLES. A trilogia tebana: Édipo rei, Édipo em Colono, Antígona. Rio de Janeiro: Jorge Zahar Editor, 15ª Edição, 2011. 